\title{
Prescribing patterns in the management of arthritis in a rural tertiary care teaching hospital
}

\author{
Neha K. ${ }^{1 *}$, Ravi Shankar M. ${ }^{2}$
}

\begin{abstract}
${ }^{1}$ Department of Pharmacology, Sree Mookambika Institute of Medical Sciences (SMIMS), Kanyakumari, Tamil Nadu, India

${ }^{2}$ Department of Pharmacology, Adichunchanagiri Institute of Medical Sciences (A.I.M.S), B. G. Nagara, Nagamangala Taluk, Mandya, Karnataka, India
\end{abstract}

Received: 14 October 2020

Revised: 21 November 2020

Accepted: 30 November 2020

\author{
*Correspondence: \\ Dr. Neha K. \\ Email: nh.nandan@gmail.com
}

Copyright: (c) the author(s), publisher and licensee Medip Academy. This is an open-access article distributed under the terms of the Creative Commons Attribution Non-Commercial License, which permits unrestricted non-commercial use, distribution, and reproduction in any medium, provided the original work is properly cited.

\begin{abstract}
Background: Based on 2003 National Health Insurance Scheme (NHIS) data, a projected 67 million (25\%) adults aged 18 years or older will have arthritis and 25 million (37\%) of those will have arthritis-attributable activity limitations by the year 2030. Objective of this study is to know the prevalence of different types of arthritis, current trends of drug prescribing patterns in its management and to create awareness about rational use of drugs in a rural tertiary care hospital.

Methods: This was an observational study of drug prescriptions among 100 arthritis patients in a tertiary care teaching hospital, India. Patients diagnosed with arthritis with or without co-morbidities were enrolled in the study considering the inclusion and exclusion criteria with a verbal informed consent.

Results: Out of 100 arthritis cases, prevalence of Osteoarthritis (OA) was seen more than Rheumatoid arthritis (RA). Osteoarthritis was more commonly seen in males and RA in females. Arthritis was more prevalent in the age group of 36-65 years. Oral route was the most preferred route of administration of drugs and Nonsteroidal anti-inflammatory drugs (NSAIDs) were the first choice. Vitamin D3+ calcium was the most commonly prescribed drug in arthritis. Diclofenac was the most commonly used drug for monotherapy in OA and methotrexate in RA.

Conclusions: In this study, some patients diagnosed with RA were treated with NSAIDs as first line and no Disease Modifying Anti-Rheumatic Drugs (DMARD) were given. This irrational prescribing trend should be changed. Nonpharmacological treatment has a qualitative role in treating arthritis and should be advised instead of multiple drug therapy.
\end{abstract}

Keywords: Prescribing patterns, Arthritis, Osteoarthritis, Rheumatoid arthritis, Nonsteroidal anti-inflammatory drugs, Disease modifying anti-rheumatic drugs, Vitamin D3+ calcium

\section{INTRODUCTION}

Drug utilization research was defined by World Health Organization (WHO) in 1977 as the marketing, distribution, prescription, and use of drugs in a society, with special emphasis on the resulting medical, social and economic consequences. ${ }^{1}$

Prescription writing can be depicted as an art. Since, it reflects the directions given by the prescriber to the patient or their representatives. ${ }^{2}$ Therefore, a prescription written 
by a physician is a reflection of his perspective towards the particular disease and the role of drug in its treatment. It also provides an apprehension into the essence of the health care delivery system. ${ }^{3}$

Rational drug prescribing can be defined as appropriate drugs prescribed in the right dose, at correct time intervals and for a sufficient duration. Irrational drug use is a common problem in many countries of the world. ${ }^{4}$ The assessment of drug utilization is important for clinical, economic and educational purposes. ${ }^{5}$

Periodic evaluation of drug utilization patterns need to be done to enable suitable modifications in prescription of drugs to increase the therapeutic benefit and decrease the adverse effects. The study of prescribing patterns seeks to monitor, evaluate and if necessary, suggest modifications in the prescribing behaviour of medical practitioners to make medical care rational and cost effective. ${ }^{6}$

Arthritis is an acute or chronic inflammation of joint, often accompanied by pain, swelling and stiffness and resulting from infection or injury. Pain is the most common symptom and is associated with bad functional outcomes and poor quality of life. Different kinds of arthritis are, widely spread among the population that make them a clinical problem with social, psychological and economic burden. The management of arthritis is complex and relies on a combination of pharmacological and nonpharmacological approaches including drug treatment, for most of the patients; management of arthritis relies mainly on optimization of pharmacotherapy. Unfortunately, there are many reports of extra medication because of pain. This misuse leads to intoxication and occurrence of adverse drug reactions, hospitalizations, and additional treatment and from there to increase in treatment cost. The treatment options have primarily focused on alleviating the pain associated with this condition. ${ }^{7}$

The term arthritis literally means "joint inflammation", but it is generally used to refer to a family of more than 100 different conditions that affect the joints and may also affect muscles and other tissues. The most common form of arthritis- degenerative arthritis or osteoarthritis (OA) which results from the breakdown of the tissue inside the joints. The other form is inflammatory arthritis which results from swelling in the joints. Rheumatoid arthritis (RA) is a most common type of inflammatory arthritis. ${ }^{8}$

The prevalence of osteoarthritis in India is very high. Based on 2010-2012 data from the National Health Interview Survey (NHIS), an estimated 52.5 million $(22.7 \%)$ of adults have self-reported doctor- diagnosed arthritis. 22.7 million (9.8\% of all adults) have arthritis and arthritis attributable activity limitation. Based on 2003 NHIS data a projected 67 million (25\%) adults aged 18 years or older will have doctor-diagnosed arthritis by the year 2030. An estimated 37\% (25 million adults) of those with arthritis will report arthritis-attributable activity limitations by the year $2030 .^{9}$
Approximately $1 \%$ of the adult population is affected by RA worldwide. Its incidence is 2 to 3 times greater in women, and this disproportion is most evident in patients younger than 50 years. Until about the 7 th decade of life, the incidence of RA continues to increase with age. Approximately, about $0.75 \%$ of adult Indian population is negatively affected by the disease which hampers the patients' quality of life. ${ }^{10}$

Hence the current study is undertaken to evaluate quality indicators in drug utilization patterns and to create awareness about rational use of drugs.

Objective of this study is to know the prevalence of different types of arthritis, demographic characteristics of the patients and the current trends of drug prescribing patterns in the management of arthritis in a rural tertiary care teaching hospital.

\section{METHODS}

This study was conducted at Adichunchanagiri institute of medical sciences (AIMS), B.G. Nagara, Mandya, Karnataka, India.

\section{Study design}

The study was a prospective observational study.

\section{Study population}

100 cases of arthritis patients were analysed.

Ethical clearance was taken from the Institutional Ethics Committee (IEC) of AIMS, B.G. Nagara, Karnataka, India.

\section{Procedure}

The study was conducted from patients of orthopaedic, paediatrics and medicine departments at Adichunchanagiri Institute of Medical Sciences (AIMS), B.G. Nagar from December 2015 to July 2017. Patients diagnosed with arthritis with or without co-morbidities were enrolled in the study considering the inclusion and exclusion criteria. Verbal informed and written consent was taken from patients at the time of enrolment in the study.

\section{Inclusion criteria}

Arthritis patients from orthopaedic, paediatrics and medicine departments. Patients who were willing to participate in the study. Patients diagnosed with arthritis with or without co-morbidities.

\section{Exclusion criteria}

Patients who were not willing to participate in the study. 


\section{Statistical analysis}

Fully completed data were analysed and expressed in percentages (\%) using Microsoft excel software.

\section{RESULTS}

Out of 100 cases, arthritis was more commonly seen in male patients than female patient (Table 1).

$\mathrm{OA}$ and RA were more prevalent in the age group of 3665 years (Table 2). Prevalence of OA was more than RA (Table 3). More number of drugs are prescribed per prescription rather than single drug (Table 4). Oral route was the most preferred route of administration in the management of both OA and RA (Table 5).

NSAIDs were the first choice of drugs prescribed in both OA and RA patients (Table 6). Vitamin D3+ calcium was the most commonly prescribed drug both in OA and RA patients (Table 7). Diclofenac was the most commonly used drug for monotherapy in OA (Table 8).

Analgesics were the most commonly used drugs for 2 drug therapy in OA and RA (Table 9 and 10).

Table 1: Details of gender distribution of patients $(\mathrm{n}=100)$.

\begin{tabular}{|lll|}
\hline $\begin{array}{l}\text { Gender } \\
\text { distribution }\end{array}$ & $\begin{array}{l}\text { Number of } \\
\text { patients }\end{array}$ & Percentage (\%) \\
\hline Male & 58 & 58 \\
\hline Female & 42 & 42 \\
\hline Total & 100 & 100 \\
\hline
\end{tabular}

Table 1 shows that generally Arthritis is more commonly seen in male patients $58(58 \%)$ than female patients 42 $(42 \%)$.

Table 2: Details of age distribution of patients $(n=100)$.

\begin{tabular}{|lll|}
\hline $\begin{array}{l}\text { Age } \\
\text { distribution } \\
\text { (years) }\end{array}$ & $\begin{array}{l}\text { Number of } \\
\text { patients }\end{array}$ & Percentage (\%) \\
\hline $\mathbf{2 0 - 3 5}$ & 5 & 5 \\
\hline $\mathbf{3 6 - 5 0}$ & 25 & 25 \\
\hline $\mathbf{5 1 - 6 5}$ & 59 & 59 \\
\hline $\mathbf{6 6 - 8 0}$ & 10 & 10 \\
\hline $\mathbf{> 8 0}$ & 1 & 1 \\
\hline Total & 100 & 100 \\
\hline
\end{tabular}

Table 3: Details of disease distribution $(n=100)$.

\begin{tabular}{|lll|}
\hline Disease & $\begin{array}{l}\text { Number of } \\
\text { patients }\end{array}$ & Percentage (\%) \\
\hline Osteoarthritis & 84 & 84 \\
\hline $\begin{array}{l}\text { Rheumatoid } \\
\text { arthritis }\end{array}$ & 16 & 16 \\
\hline Total & 100 & 100 \\
\hline
\end{tabular}

Table 2 shows the age wise distribution of RA and OA patient and the result revealed that both RA and OA were more prevalent in the age group of 36-65 years $(25 \%+59 \%=84 \%)$.

Table 3 shows that prevalence of OA 84 (84\%) is more than RA $16(16 \%)$.

Table 4: Number of drugs per prescription $(n=100)$.

\begin{tabular}{|lll|}
\hline $\begin{array}{l}\text { Number of } \\
\text { drugs }\end{array}$ & $\begin{array}{l}\text { Number of } \\
\text { prescriptions }\end{array}$ & Percentage $(\%)$ \\
\hline $\mathbf{1}$ & 0 & 0 \\
\hline $\mathbf{2}$ & 15 & 15 \\
\hline $\mathbf{3}$ & 63 & 63 \\
\hline $\mathbf{4}$ & 13 & 13 \\
\hline $\mathbf{5}$ & 7 & 7 \\
\hline $\mathbf{6}$ & 2 & 2 \\
\hline Total & 100 & 100 \\
\hline
\end{tabular}

Table 4 shows that more number of drugs are prescribed per prescription rather than single drug.

Table 5: Details of route of drug administration $(\mathbf{n}=318)$.

\begin{tabular}{|lll|} 
Route & $\begin{array}{l}\text { Number of } \\
\text { drugs } \\
\text { prescribed }\end{array}$ & Percentage (\%) \\
\hline Oral & 219 & 68.86 \\
\hline Topical & 63 & 19.81 \\
\hline Injectable & 36 & 11.32 \\
\hline Total & 318 & 100 \\
\hline
\end{tabular}

Table 5 shows that oral route $219(68.86 \%)$ is the most preferable route of administration in the management of arthritis followed by topical $63(19.81 \%)$ and Injectable $36(11.32 \%)$.

Table 6: Details of class of drugs prescribed $(n=249)$.

\begin{tabular}{|lll|}
\hline Class of Drugs & $\begin{array}{l}\text { Number of } \\
\text { Drugs } \\
\text { prescribed }\end{array}$ & Percentage (\%) \\
\hline NSAIDs & 105 & 42.16 \\
\hline Opiod analgesics & 29 & 11.64 \\
\hline Corticosteroids & 34 & 13.65 \\
\hline $\begin{array}{l}\text { Multivitamins } \\
\text { and minerals }\end{array}$ & 69 & 27.71 \\
\hline DMARDs & 12 & 4.81 \\
\hline Total & 249 & 100 \\
\hline
\end{tabular}

Table 6 shows that NSAIDs $105(42.16 \%)$ are the first choice of drugs used in the management of arthritis followed by vitamin D3+ calcium $69(27.71 \%)$.

Table 7 shows that vitamin D3+ calcium 69 (34.15\%) was the most commonly used drug. 
Table 8 shows that diclofenac are the most commonly used drug for monotherapy in OA 8 (40\%).

Table 7: Details of drugs prescribed single / combination $(n=202)$.

\begin{tabular}{|lll|}
\hline Drug name & $\begin{array}{l}\text { Number of } \\
\text { prescriptions }\end{array}$ & $\begin{array}{l}\text { Percentage } \\
(\%)\end{array}$ \\
\hline Diclofenac & 12 & 5.94 \\
\hline Aceclofenac & 5 & 2.47 \\
\hline Paracetamol & 11 & 5.44 \\
\hline Hydroxychloroquine & 4 & 1.98 \\
\hline Methotrexate & 8 & 3.96 \\
\hline Prednisolone & 15 & 7.42 \\
\hline Deflazacort & 19 & 9.4 \\
\hline Tramadol & 12 & 5.94 \\
\hline $\begin{array}{l}\text { Calcium + Vitamin } \\
\text { D3 }\end{array}$ & 69 & 34.15 \\
\hline $\begin{array}{l}\text { Diclofenac }+ \\
\text { Paracetamol }\end{array}$ & 12 & 5.94 \\
\hline $\begin{array}{l}\text { Aceclofenac }+ \\
\text { Paracetamol }\end{array}$ & 18 & 8.91 \\
\hline $\begin{array}{l}\text { Aceclofenac }+ \\
\text { Tramadol }\end{array}$ & 17 & 8.41 \\
\hline Total & 202 & 100 \\
\hline
\end{tabular}

Table 8: Details of drugs used in monotherapy in OA $(n=20)$.

\begin{tabular}{|lll|}
\hline Drug name & $\begin{array}{l}\text { Number of } \\
\text { prescriptions }\end{array}$ & $\begin{array}{l}\text { Percentage } \\
(\%)\end{array}$ \\
\hline Diclofenac & 8 & 40 \\
\hline Aceclofenac & 3 & 15 \\
\hline Paracetamol & 5 & 25 \\
\hline Tramadol & 4 & 20 \\
\hline Total & 20 & 100 \\
\hline
\end{tabular}

Table 9: Details of drugs used in 2 drug therapy in OA $(n=42)$.

\begin{tabular}{|lll|}
\hline 2 Drug Therapy & $\begin{array}{l}\text { Number } \\
\text { of } \\
\text { patients }\end{array}$ & $\begin{array}{l}\text { Percentage } \\
(\%)\end{array}$ \\
\hline NSAIDs + NSAIDs & 22 & 52.38 \\
\hline $\begin{array}{l}\text { Aceclofenac + } \\
\text { Paracetamol }\end{array}$ & 12 & 28.57 \\
\hline Diclofenac + Paracetamol & 10 & 23.8 \\
\hline NSAIDs + Steroid & 8 & 19.04 \\
\hline Diclofenac + Deflazacort & 5 & 11.9 \\
\hline $\begin{array}{l}\text { Diclofenac + } \\
\text { Prednisolone }\end{array}$ & 3 & 7.14 \\
\hline $\begin{array}{l}\text { NSAIDs + Opioid } \\
\text { analgesic }\end{array}$ & 12 & 28.57 \\
\hline Aceclofenac + Tramadol & 4 & 9.52 \\
\hline Paracetamol + Tramadol & 5 & 11.9 \\
\hline Diclofenac + Tramadol & 3 & 7.14 \\
\hline Total & 42 & 100 \\
\hline
\end{tabular}

Table 9 shows that NSAIDs + NSAIDs are the most commonly used drugs for 2 drug therapy in OA 22 $(52.38 \%)$.

Table 10 shows that NSAIDs + Opioid analgesics are the most commonly used drugs for 2 drug therapy in RA 5 $(55.55 \%)$.

Table 10: Details of drugs used in 2 drug therapy in $\operatorname{RA}(\mathbf{n}=9)$.

\begin{tabular}{|lll|}
\hline Drug therapy & $\begin{array}{l}\text { Number } \\
\text { of patients }\end{array}$ & $\begin{array}{l}\text { Percentage } \\
(\%)\end{array}$ \\
\hline DMARDs + DMARDs & 1 & 11.11 \\
\hline $\begin{array}{l}\text { Hydroxychloroquine + } \\
\text { Methotrexate }\end{array}$ & 1 & 11.11 \\
\hline NSAIDs + DMARDs & 3 & 33.33 \\
\hline $\begin{array}{l}\text { Aceclofenac + } \\
\text { Methotrexate }\end{array}$ & 3 & 33.33 \\
\hline $\begin{array}{l}\text { NSAIDs + Opioid } \\
\text { analgesic }\end{array}$ & 5 & 55.55 \\
\hline $\begin{array}{l}\text { Aceclofenac }+ \\
\text { Tramadol }\end{array}$ & 5 & 55.55 \\
\hline Total & 9 & 100 \\
\hline
\end{tabular}

\section{DISCUSSION}

\section{Gender}

The study shows that RA was commonly seen in female patients $13(81.25 \%)$ than male patients $3(18.75 \%)$ which was in accordance with the conducted by Ahmed et al and Premkumar et al, also OA was more common in male 49 $(58.33 \%)$ patients than female patient $35(41.66 \%)$ which was in accordance with the study conducted by Ahmed et al. ${ }^{11}$ Hence, this study revealed that the gender distribution in OA and RA found to be more in males than in females.

Age

Age distribution in OA was found to be more prevalent in the age group between 51-65 years $51(60.71 \%)$ and age distribution in RA was found to be more in the age group of 36-65 years 14 (87.5\%). This study reveals that, both OA and RA were more prevalent in the age group of years 3665 years which was found to be in accordance with the study conducted by Ahmed et al and Gurung et al. ${ }^{12}$

\section{Prevalence of disease}

The study shows that prevalence of OA $84(84 \%)$ is more than RA $16(16 \%)$ which was in accordance with the conducted by Ahmed et al and Gurung et al. ${ }^{13}$

\section{Drug nomenclature}

The study shows that brand name (79\%) were more commonly used than generic name $(21 \%)$. 


\section{Number of drugs per prescription}

The study shows that maximum number of prescription contains about 3 drugs $63(63 \%)$ and in a case of RA maximum number of prescription contains about 4 drugs 7 $(43.75 \%)$ and in $\mathrm{OA}$ maximum number of prescription contains about 3 drugs 61 (72.61\%).

\section{Route of administration}

It was observed in the study that drugs were prescribed by oral route $61(85.91 \%)$ is the most preferable route of administration in the management of rheumatoid arthritis followed by injectable $8(11.26 \%)$ and topical route 2 $(2.81 \%)$ which was in accordance with the conducted by Gurung et al and in case of OA that 158 (63.96\%) drugs were prescribed by oral route followed by topical route 61 (24.69\%) and injectable $28(11.33 \%)$. This was found to be in accordance by the study conducted by Ahmed et al.

\section{Classes of drugs prescribed}

The results revealed that NSAIDs 105 (42.16\%) were the first choice of drugs prescribed in both OA and RA patients. In OA, NSAIDs $82(44.08 \%)$ were the first choice of drugs followed by vitamin D3+ calcium 58 (31.18\%) which was in accordance with the study conducted by Ahmed et al and in RA, NSAIDs $23(36.5 \%)$ were first choice followed by DMARDs $12(19.04 \%)$ which was contrast to the study conducted by Ahmed et al.

\section{Drugs prescribed}

The study shows that vitamin D3+ calcium was the most commonly prescribed drug both in OA and RA patients 69 (34.15\%) followed by Deflazacort 19 (9.4\%) and Aceclofenac+PCT $18(8.91 \%)$ which was found to be in contrast with the study conducted by Ahmed et al and Gurung et al.

\section{Approach of management of arthritis}

The study shows that more number of OA patients were treated with combination therapy $64(76.19 \%)$ than monotherapy $20(23.8 \%)$ and more number of RA patients were treated with monotherapy $10 \quad(62.5 \%)$ than combination therapy $6(37.5 \%)$ which was found to be in accordance with the study conducted by Ahmed et al and Gurung et al.

The study shows that Diclofenac was the most commonly used drug for monotherapy in OA $8(40 \%)$ which was found to be in accordance with Purushottam et al and Ahmed et al and Gurung et al and Methotrexate was the only drug used for monotherapy in RA 10 (100\%). ${ }^{14}$

In combination therapy more number of patients were treated with 2 drug therapy $51(63.75 \%)$ followed by 29 $(36.25 \%)$ patients with 3 or more drug therapy.
In two drug therapy, in OA, out of 42 patients, 22 (52.38\%) patients were prescribed with a combination of NSAIDs + NSAIDs, followed by other drug combinations and in RA, out of 9 patients, $5(55.55 \%)$ were prescribed with a combination of NSAIDs + opioid analgesics followed by other drug combinations.

The results revealed that in $\mathrm{OA}$, out of 22 patients treated with 3 or more drug therapy, $10(45.45 \%)$ patients were treated with NSAIDs + NSAIDs + vitamin D3 + calcium, followed by other drug combinations and in RA, out of 7 patients treated with 3 or more drug therapy, $4(57.14 \%)$ patients were treated with NSAIDs + NSAIDs + Opioid analgesics, followed by other drug combinations.

Though literature says DMARDs should be given as first line as soon as patient is diagnosed with rheumatoid arthritis. Here, in some patients diagnosed with RA were irrationally treated with NSAIDs as first line and no DMARDs were given. This may lead to progression of the disease. This may be due to patient unable to afford the drugs, lack of knowledge about the disease, lack of adherence to the treatment and this being a private hospital, DMARDs are not freely available.

\section{CONCLUSION}

The present study shows that OA is the most common type of arthritis. RA was commonly seen in female patients and OA was more common in male patients. Age distribution in OA was found to be more prevalent in the age group between 51-65 years and in RA was found to be more in the age group of 36-65 years. The study reveals that, both $\mathrm{OA}$ and RA were more prevalent in the age group of years $36-65$ years. Oral route $61(85.91 \%)$ is the most preferable route of administration in the management of arthritis. More number of patients were treated with combination therapy than monotherapy. NSAIDs were the first choice of drugs prescribed in both OA and RA patients. Vitamin D3+calcium was the most commonly prescribed drug both in $\mathrm{OA}$ and RA patients. Diclofenac was the most commonly used drug for monotherapy in OA and Methotrexate was the only drug used for monotherapy in RA.

In this study, some patients diagnosed with RA were irrationally treated with NSAIDs as first line and no DMARDs were given. Therefore, one should take proper interventions to change such irrational prescribing trends. Non-pharmacological treatment has a qualitative role in treating arthritis. There were very few prescriptions of nondrug therapy such as physiotherapy and exercise. So, instead of taking multiple drug therapy one should also advise patient regarding the non-pharmacological treatments and their benefits.

\section{ACKNOWLEDGEMENTS}

We express our thankfulness to undergraduates, postgraduates, teaching faculty in our institution, 
institutional ethics committee for facilitating the smooth conduct of the study.

Funding: No funding sources

Conflict of interest: None declared

Ethical approval: The study was approved by the Institutional Ethics Committee

\section{REFERENCES}

1. Birkett D, Smet PD, Adjei DO, Trolin I, Bergman U, Strom $\mathrm{H}$, et al. Introduction to Drug Utilization Research. WHO. 2003;6-9. Accessed on 11 September 2020.

2. Shirpa J, Zafar KY, Prerna U, Kumar A. Assessment of Prescribing Pattern in a Private Teaching Hospital in India. International Journal of Pharma Sciences. 2012;3(3):219-22.

3. Shaikh U, Chandra SN, T J, Shankar J, Kotipalli R. Prescription Trends in department of Orthopaedics at Tertiary Care Teaching Hospital. Journal of Chemical and Pharmaceutical Research. 2013;5(11):512-17.

4. Hogerzeil HV. Promoting rational prescribing: an international perspective. $\mathrm{Br} \mathrm{J}$ Clin Pharmacol. 1995;39:1-6.

5. Uppal R, Nayak P, Sharma PL. Prescribing trends in internal medicine. Int $\mathrm{J}$ Clin Pharm Ther Toxicol. 1984;22:373-76.

6. Shankar PR, Pai R, Dubey AK, Upadhyay DK. Kathmandu university medical journal. 2007;5(17):16-21.

7. Velentina BP. Pharmacy practice. 2009;7(2):88-93.

8. A leading cause of disability in the United States. Arthritis: National Academy On An Aging Society. 2000;(5):1-6.

9. Arthritis: Data and Statistics. CDC. 2015. Available from: http://www.cdc.gov/arthritis/data_statistics/index.htm 1. Accessed on 10 September 2020.

10. Grijalva GC, Chung PC, Stein. MC, Jr Mitchel. FE, Griffin RM. Changing patterns of medicine use in patients with Rheumatoid arthritis in a Medical population USA. Oxford University Press,. 2008;47:1061-64.

11. B. Premkumar, Srinivasamurthy M, Rajagopal K. A Retrospective Study on Clinical Characteristics of Rheumatoid Arthritis Patients. Biomedical \& Pharmacology Journal. 2013;6(2):471-475

12. Ahmed M, Ali N, Rahman ZU, Khan MM. A study on prescribing patterns in the management of arthritis in the department of orthopedics. Der Pharmacia Lettre. 2012;4(1):5-27.

13. Gurung S, Babu S, Sabu S, Shibu RM, Begum R, Nanjwade BK. A study on prescribing pattern in the management of osteoarthritis and rheumatoid arthritis in the department of orthopaedics. World journal of pharmacy and pharmaceutical sciences. 2016;5(4):1472-93.

14. Jhanwar P, Pandey S, Sharma N, Jhanwar A. Drug utilization study of osteoarthritis in a tertiary care teaching hospital of rajasthan. International journal of pharmaceutical sciences review and research. 2012;14(2):35-7.

Cite this article as: K N, M RS. Prescribing patterns in the management of arthritis in a rural tertiary care teaching hospital. Int J Basic Clin Pharmacol

2021;10:49-54. 